\title{
ᄂ

Estudio de las cadenas de abastecimiento de germoplasma forestal en Ecuador

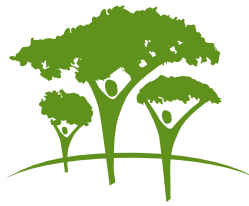



Estudio de las cadenas de abastecimiento de germoplasma forestal en Ecuador 


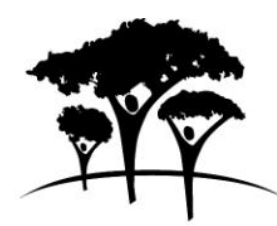

World Agroforestry Centre

TRANSFORMING LIVES AND LANDSCAPES

Citación correcta:

Prado L, Samaniego, C, Ugarte-Guerra, J. 2010. Estudio de las cadenas de abastecimiento de germoplasma forestal en Ecuador. ICRAF Working Paper no. 115. World Agroforestry Centre (ICRAF). Lima, Perú.

Los títulos en esta Serie de Documentos de Trabajo tienen el objetivo de diseminar resultados preliminares sobre investigación y prácticas en agroforestería y estimular la retroalimentación de la comunidad científica. Otras series de publicaciones del World Agroforestry Centre incluyen: Manuales Técnicos y Artículos Ocasionales.

Publicado por el World Agroforestry Centre (ICRAF)

Av. La Universidad $\mathrm{s} / \mathrm{n}$

c/o Centro Internacional de la Papa (CIP)

P.O. Box 1558, Lima 12

Lima, Perú

Tel: $+51(1) 3496017$

Fax: +51(1) 3496021

Email: $\underline{\text { s.dupuy@cgiar.org }}$

Internet: www.worldagroforestry.org

(c) ASB-World Agroforestry Centre 2010

Working Paper no. 115

Las opiniones expresadas en esta publicación son de loa autores y no necesariamente del Centro Mundial de Agroforestería.

Los artículos que aparecen en esta publicación pueden ser citados o reproducidos sin costo siempre que la fuente sea reconocida.

Todas las imágenes son de propiedad de la fuente y no pueden ser usada por ningún motivo sin permiso de la fuente. 


\section{Sobre los autores}

Lenin Prado

Carlos

Rojas

Samaniego

Julio Ugarte-Guerra
Ingeniero Forestal por la Universidad Técnica "Luis Vargas Torres", Esmeraldas, Ecuador, con una Maestría en Conservación y Gestión del Medio Natural por la Universidad Internacional de Andalucía, España. Actualmente es Jefe del Area de Proyecto del Municipio de Esmeraldas, Ecuador.

Ingeniero Forestal. Actualmente se desempeña como consultor en temas de producción de semilla, con sede en Ecuador.

Julio Ugarte es Ingeniero Forestal y Magíster Scientiae en Gestión de Bosques y Recursos Forestales por la Universidad Nacional Agraria La Molina y Master en Administración (EADA). Actualmente se desempeña como representante nacional del Centro Mundial para la Agroforestería, ICRAF, con sede en Lima, Perú. 


\section{Resumen Ejecutivo}

En la mayoría de los países andinos gran parte de los programas de plantaciones forestales han basado su desarrollo con la utilización de semillas de calidad física, fisiológica y genética desconocida, sea de fuentes locales o importadas con consecuencias desfavorables para el potencial futuro del desarrollo forestal.

En el Ecuador la problemática de semillas forestales era poco analizada a pesar de que constituye el núcleo de la actividad de forestación y reforestación, eso se debía a que muchas de las acciones de generación de leyes, aplicación y control se encontraba dentro de u estado con tradición centralista, siendo en ocasiones juez y parte de las acciones del sector forestal.

Sin embargo algunos proyectos importantes han promovido mayores regulaciones en el mercado de semillas forestales, este mercado creciente cubre las demandas del sector público y privado, y se espera que en el futuro próximo las inversiones publicas sean un importante vehiculo para incrementar el tamaño del mercado local, la implementación del reglamento de semillas forestales, ya aprobado, debería ser el instrumento para que el consumidor este claramente informado de la calidad del producto que compra. A pesar de existir un activo sector privado en el mercado de semilla sus flujos al exterior no son significativos, aparentemente por que cuentan ya con sus propias fuentes de abastecimiento.

\section{Palabras clave}

Agroforesteria. Germoplasma, recursos genticos forestales, semillas, Ecuador,

\section{Agradecimientos}

Se agradece la generosa contribución de la Comunidad Europea, sin cuyo aporte este trabajo no hubiera sido posible, además de la contribución del Instituto nacional de Innovación agropecuaria (INIA). Los autores agradecen a Pedro Ruiz, Dora Samaniego, Zoila Vela y Tania Einfeldt por sus importantes contribuciones al manuscrito. 


\section{ESTUDIO DE MERCADO DE SEMILLAS FORESTALES EN LA AMAZONIA}

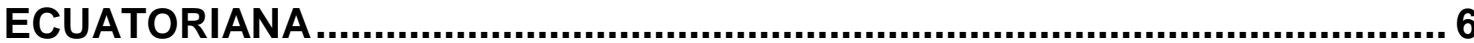

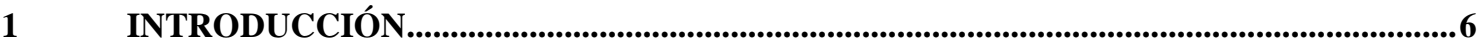

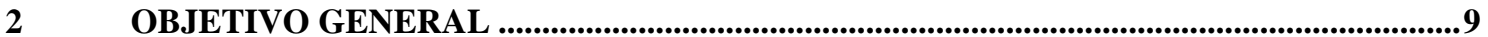

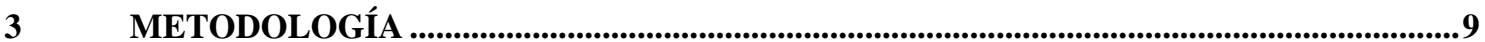

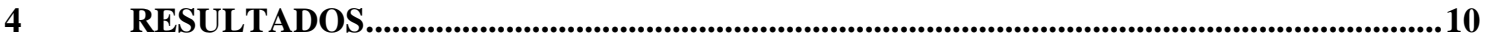

4.1 Actores del mercado y su caracterización .........................................................................10

$4.2 \quad$ Oferta de semillas ..............................................................................................................................17

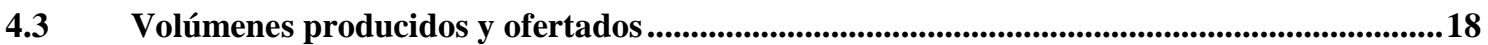

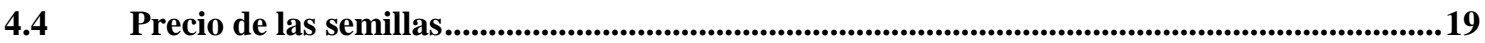

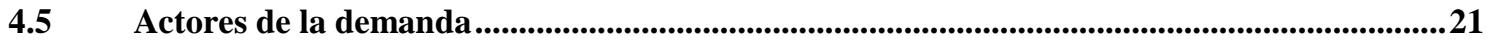

4.6 Demanda de semillas especies prioritarias..........................................................................22

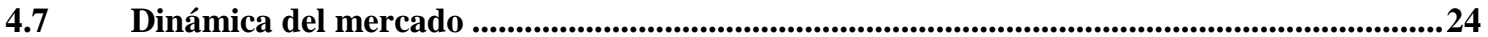

4.8 Experiencias en la región y síntesis del mercado de semillas forestales en la región andina de Bolivia, Ecuador y Perú...................................................................................................................25

5 CONCLUSIONES: ..........................................................................................................................26

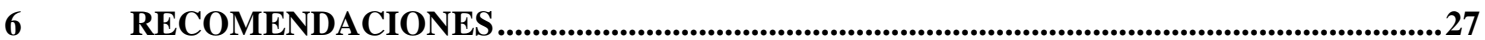

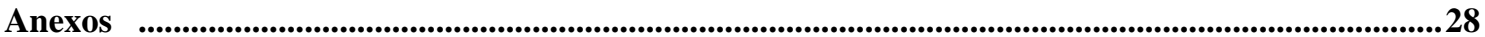

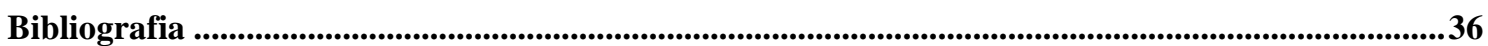




\title{
ESTUDIO DE MERCADO DE SEMILLAS FORESTALES EN LA AMAZONIA ECUATORIANA
}

\author{
Lenin Prado Rodríguez
}

Carlos Samaniego Rojas

\section{$1 \quad$ INTRODUCCIÓN}

El Ecuador es considerado un país con vocación forestal, sin embargo, este sector aporta poco a la economía de la nación, más tiene una balanza comercial negativa. La gestión administrativa del sector forestal ha sido encomendada a diferentes ministerios e instituciones con limitada participación de la comunidad forestal; aplicando políticas, estrategias, planes y programas cuyo resultado actual es la pérdida de más de la mitad de nuestros bosques dando como resultado el empobrecimiento y deterioro social de la mayoría de ecuatorianos (Bodero y Prado 2008).

El bosque tropical húmedo de la costa ha sido ocupado en más del $75 \%$ para la agricultura, seguido por el bosque seco occidental y la vegetación interandina con más del $70 \%$ de ocupación. La deforestación del bosque tropical durante el periodo comprendido entre los años 1991 al 2000 fue de 1' 782.832 ha que corresponde a una deforestación neta anual de 198.092 ha. Sin embargo, la reforestación en los últimos 20 años no alcanzaría más de 150mil ha, cifras que no se compadecen con lo deforestado. Los índices más altos de deforestación se encuentran en la Región Amazónica, debido principalmente a las actividades petroleras, la construcción de vías de acceso y la consecuente migración y ampliación de la frontera agrícola. En la amazonía existen varios programas forestales y agroforestales de tipo social que buscan mejorar las condiciones agroforestales de las fincas, generar ingresos familiares, reducir la explotación de los bosques nativos y conservación de la vegetación nativa existente. Los programas son impulsados por los gobiernos locales, ONGs, entidades privadas que tratan de establecer masas boscosas, pero por la escasa disponibilidad de semillas de especies forestales nativas, la falta de tecnologías apropiadas para el manejo de fuentes semilleras, semillas y manejo silvicultural de las especies, están relegados a incumplir las planificaciones establecidas.

En la región andina de Bolivia, Ecuador y Perú se desarrollaron programas forestales y agroforestales sociales que estaban insertados en los sistemas de producción campesinos, en el manejo de cuencas hidrográficas y en la conservación de suelos en laderas. Los programas tenían como propósito garantizar la capacidad productiva de los ecosistemas, diversificar la producción campesina y mantener la diversidad biológica. En la década del 90, la mayoría de esos programas no consideró la calidad del material reproductivo para la producción de plantones, como consecuencia las plantaciones tenían un pobre crecimiento y limitado desarrollo. Así mismo, los mercados de semillas locales no logran abastecer de semillas en cantidad, calidad de forma oportuna. A partir del año 2000 por iniciativa del Programa de Fomento de Semillas Forestales - FOSEFOR que funcionaba en la región andina de tres países (Bolivia, Ecuador y Perú), la situación empezó a cambiar. Se trabajó bajo la dinámica de acción descentralizada, en el caso de las semillas forestales se incorporó a actores públicos y privados de la oferta y demanda de semillas para profundizar en el diagnóstico de situación y asegurar su seguimiento (tipología de actores, árbol de problemas y de potencialidades) y precisar necesidades de acción y ofertas de colaboración y se reconoce que plantaciones forestales tienen bajo rendimiento y desarrollo debido a que el material genético utilizado es de procedencia y calidad desconocida.

Entre los principales problemas identificados encontramos:

La poca disponibilidad de semillas forestales de calidad en cantidad, suministro oportuno y permanente para cubrir la demanda de los actores y el desconocimiento de las técnicas de producción, procesamiento y almacenamiento de semillas forestales de muchas especies nativas que garanticen la viabilidad de las mismas.

- La falta de un directorio de productores, oferentes, demandantes y comercializadores de semillas que ayude a los actores a mantener contactos y promoción de productos dado que el Ministerio del Ambiente no está realizando la función de normar y regular el uso de semillas 
dentro de las acciones forestales desarrolladas, esto no ayuda a orientar a los usuarios sobre las ventajas de las semillas de calidad.

Limitada información técnica y científica sobre las especies forestales nativas de interés que facilite un mejor conocimiento de los usuarios y poca disponibilidad de fuentes semilleras y de árboles semilleros de especies nativas y exóticas que garanticen una producción sostenida y de bajos costos.

- Elevados costos de producción de semillas nativas por las distancias en que se encuentran los árboles y fuentes semilleras e inexistencia de un registro nacional de fuentes semilleras clasificadas y evaluadas, y una institución que disponga de base de datos sobre dichos registros en donde los usuarios puedan acceder a la información con facilidad.

Existe poco acercamiento entre los actores que trabajan en este tema que facilite la difusión de sus experiencias existentes y posibilite conocer los avances desarrollados en torno a las semillas y los precios de compra y venta de las semillas son variables dentro de una misma especie y nadie garantiza la calidad al momento de la adquisición. Además, no existe una cultura de adquirir semillas por calidad sino por precio.

- Las instituciones, organizaciones y proyectos no disponen de registros respecto a la producción de semillas y plantas, ni de calendarios fenológicos adecuados para la recolección oportuna del material.

A nivel de la región en general, existen limitados conocimientos y trabajos de investigación desarrollados en mejoramiento de semillas forestales con especies nativas.

- Existen limitadas acciones demostrativas de campo sobre plantaciones establecidas con semillas de calidad ver sus resultados con semilla corriente.

La gran mayoría de actores semilleros desconocen los criterios que definen la calidad y procedencia de las semillas, lo cual dificulta la adquisición adecuada del material en los lugares donde la compran.

- El sector informal del mercado de semillas es amplio y difícil de convocar, sería importante tecnificarlo en la producción, procesamiento, almacenamiento, mercadeo, promoción y difusión del material genético que ofertan; igual caso podría ser para los demandantes.

Aún existe limitada capacitación organizada y secuencial en manejo de semillas y plantas nativas que garantice una evolución en los conocimientos de los actores y estimule la demanda del uso de material de calidad.

Por desconocer la información técnica respecto a la calidad y procedencia de la semilla, los actores están obligados a adquirir más semilla de lo necesario para una determinada producción de plantas, lo que significa que no pueden planificar con certeza la producción de plantas. Esto ocasiona pérdidas económicas por el desperdicio de material y tiempo del personal.

Los estudios de mercados regionales de semillas forestales (Ecuador, Bolivia y Perú) realizados entre 2000 - 2006, reportan para el Ecuador dos grandes grupos de demandantes, los proyectos de cooperación internacional y el conjunto compuesto por ONGs e instituciones públicas y privadas.

A nivel general, existen limitados procesos organizativos que estimulan la tecnificación y regulación del uso de material de calidad. Por esto quizás, la principal estrategia para ingresar en el mercado de semillas es la organización de los actores con la finalidad de estandarizar los procesos técnicos de producción y manejo, disponer de semillas en forma continua, diversificar y ampliar la oferta, facilitar la adquisición al demandante y definir los precios de venta en base a la calidad.

En el 2003, Ecuador elaboró un Plan Nacional de forestación y reforestación. En el 2006 se adecúa dicho Plan para su implementación que prevé el establecimiento de 50 mil hectáreas / año de plantaciones forestales durante veinte años, en las 3 millones de hectáreas de aptitud forestal que existen. Uno de los problemas que enfrenta en Plan de Forestación y Reforestación es el abastecimiento de semillas de calidad y la disponibilidad de fuentes semilleras para especies forestales nativas prioritarias, además de la organización de los actores que intervienen en el sector forestales y la disponibilidad de tecnologías apropiadas para el manejo de plántulas en viveros y el manejo silvicultural de las plantaciones forestales nativas que utiliza, sin considerar el aspecto financiero.

Algunos organismos no gubernamentales y recientemente los gobiernos seccionales (consejos provinciales, municipios), han dedicado sus esfuerzos a la fase de producción de plantas en vivero, establecimiento de plantaciones, manejo de la plantación en los primeros años y a la sistematización de experiencias especialmente en cuanto a la propagación, como es el caso de 
algunas nativas como laurel, nogal, aliso, cedrela, caoba; sin embargo, estas experiencias han tenido limitaciones con respecto a la producción, manejo y almacenamiento de semillas, plantones y al comportamiento silvicultural de las especies.

El mercado de semillas forestales nativas en la región andina del Ecuador está caracterizado por un gran segmento informal integrado por recolectores e intermediarios que abarcan más del $60-70 \%$ de la demanda general. El sector informal del mercado de semillas es amplio y difícil de convocar. Algunos programas como FOSEFOR que actuó en la región andina de Bolivia, Ecuador y Perú hicieron esfuerzos para unificar criterios, generar metodologías, elaboración de normas de semillas, tecnificar la producción, procesamiento, almacenamiento, estudios de mercado, promoción y difusión del material genético que ofertan los actores, pero aún no se alcanzan los niveles deseables. En este sentido, aún persiste la venta informal de las semillas y no se dispone de suficientes fuentes semilleras instaladas que puedan abastecer de semillas de procedencia y calidad conocida a dichos planes y programas.

Los usuarios de las semillas también contribuyen con la oferta informal, ya que no tienen una cultura de adquirir semillas por calidad sino por precio, muchos desconocen los criterios de calidad de las semillas y las ventajas comparativas frente a una semilla corriente. A su vez los precios de compra y venta de las semillas son variables dentro de una misma especie y nadie garantiza su calidad al momento de la adquisición.

Por su parte, el Ministerio del Ambiente del Ecuador no está realizando de manera intensiva la función de normar y regular el uso de semillas dentro de las acciones forestales desarrolladas, esto no ayuda a orientar a los usuarios sobre las ventajas de las semillas de calidad.

Tanto productores como demandantes ignoran las ventajas que implica la utilización de semillas de calidad, solo por citar algunas: mayor rendimiento en las plantaciones, conocimiento de rasgos dasométricos de los futuros individuos, evitar desperdicios excesivos de semillas, reducción de personal y tiempo empleado en labores de vivero. Además, de disponer de una producción de plantones ajustadas a información técnica confiable, con lo cual se ahorra dinero y tiempo.

Por otro lado, el poco acercamiento entre los actores que trabajan en este tema no facilita la difusión de las experiencias existentes, ni posibilita conocer los avances desarrollados en torno a las semillas.

La poca disponibilidad de semillas en cantidad, suministro oportuno y permanente para cubrir la demanda de los actores, en gran parte es el resultado de la falta de integración entre los eslabones de la cadena productiva.

A nivel general, existen limitados procesos organizativos que estimulan la tecnificación y regulación del uso de material de calidad. Por esto quizás, la principal estrategia para ingresar en el mercado de semillas es la organización de los actores con la finalidad de estandarizar los procesos técnicos de producción y manejo, disponer de semillas en forma continua, diversificar y ampliar la oferta, facilitar la adquisición al demandante y definir los precios de venta en base a la calidad.

La articulación de los actores semilleros a través de un Centro Semillero contribuirá a que las instituciones, organizaciones y proyectos dispongan de germoplasma y plantones de calidad conocida de forma oportuna, sostenida y en cantidades suficientes para cubrir la demanda. También dispongan de registros respecto a la producción de semillas y plantas, así como calendarios fenológicos adecuados para la recolección oportuna del material, mejorar la planificación y ejecución eficiente de la producción de semillas y plantones en el vivero.

De igual forma, se mejorará los contactos y promoción entre productores, oferentes, demandantes y comercializadores de semillas. Se prevé además que los usuarios tengan un mayor acceso a la información técnica y científica sobre las especies nativas de su interés.

La Norma de Semillas Forestales del Ecuador, vigente desde febrero de 2004, es un instrumento que puesto en ejecución e implementación apoyará en la orientación y reglamentación del uso de semillas en el país. Con los procesos de modernización y descentralización implementados por el Estado en algunos sectores, como el forestal, la norma permitirá regular y controlar el comercio de semillas a nivel local, regional y nacional. 
La articulación de los actores semilleros a través de un centro de producción y comercialización - Centro Semillero (por regiones y con enfoque ecosistémico) contribuirá a que las instituciones, organizaciones y proyectos dispongan de registros respecto a la producción de semillas y plantas, así como calendarios fenológicos adecuados para la recolección oportuna del material. Aumentarán los contactos y promoción entre productores, oferentes, demandantes y comercializadores de semillas. De igual forma, se prevé que los usuarios tengan un mayor acceso a la información técnica y científica y experiencias innovadoras sobre las especies nativas de interés.

En el 2004 los actores que trabajan en la temática de semillas forestales financiadas por FOSEFOR, desarrollaron tres estudios de mercado de semillas forestales:

a) un estudio realizado para cinco cantones de las provincias de Cañar y Azuay (2002)

b) un estudio desarrollado para 7 cantones de la provincia de Loja (2003)

c) un estudio consolidado para las tres provincias australes Cañar, Loja y Azuay (2004)

Todos los estudios utilizaron como base los formularios de la Guía metodológica para la caracterización del mercado de semillas forestales en la región andina, dichos formatos fueron ajustados y retroalimentados para su mejor funcionalidad y análisis del mercado de semillas forestales.

\section{2}

OBJETIVO GENERAL

Describir el mercado de semillas forestales y los actores de la cadena de producción y comercialización para especies prioritarias con fines de regulación para mejorar la calidad de germoplasma en la amazonia del Ecuador.

\section{Razones para desarrollar estudios de mercados de semillas}

- Conocer los actores del mercado de semillas

- Conocer los volúmenes ofertados y demandados por especies

- Conocer las especies demandadas

- Los resultados ayudan a orientar las acciones para estimular la oferta y demanda de semillas de calidad.

- Conocer los problemas y limitaciones de los usuarios de semillas y plantas

- Conocer las experiencias existentes sobre el manejo de semillas

- Conocer los mecanismos de comercialización que utiliza el sector informal y sus tácticas de difusión y promoción del material.

- Genera información pertinente sobre la localización de las fuentes semilleras

- Ayuda a conocer a los demandantes de plantas y las acciones futuras de reforestación

- Describe donde se concentra la demanda de semillas y plantas por especies y cantones.

- Describe con certeza la calidad de semillas que se oferta y los precios de venta las mismas.

\section{METODOLOGÍA}

Elaboración de dos encuestas una para proveedores informales de semillas forestales y otra para consumidores.

Ambas encuestas fueron remitidas por correo electrónico y por vía terrestre a algunos actores de las instituciones públicas y productores de semillas de Sucumbíos y Orellana. Se elaboró un listado de los actores a través de colegas y técnicos de las organizaciones que trabajan en la temática. Con ese listado de actores se visitó durante cinco días de campo más de tres de viaje a los actores semilleros de la amazonia. Cabe señalar que los actores se encuentran muy distantes de una región a otra y no existe interacción entre éstos.

Identificación de actores de la cadena. 
Se realizó visitas de campo para identificar y contactar a los actores que intervienen en el mercado de semillas (productores y consumidores de semillas, productores de plantones y reforestadores), tanto en instituciones públicas como privadas y personas particulares. Se registraron sus datos personales y de la actividad que realizan, así como el tiempo que se encuentran trabajando en el tema semillero y producción de plantones.

- Entrevistas individuales a los miembros de la cadena de producción y comercialización de semillas identificados.

Cada uno de los actores fue entrevistado en el terreno de acuerdo con la información señalada en los formularios previamente elaborados.

- Se utilizó la técnica 'focus groups' que consiste en la realización de dinámicas grupales, sosteniendo conversaciones colectivas directas con miembros de las cadenas.

Por las distancias geográficas en las que se encuentran los actores, los escasos niveles de organización y la limitada experiencia desarrollada de forma grupal en el tema se hace difícil convocarlos y reunirlos. Además, si se desea reunir a todas estas personas hay que disponer de los fondos requeridos para el efecto. En Orellana se trabajó con los responsables de los programas de reforestación del Gobierno local y provincial. En Sucumbíos se lo hizo con los técnicos del CISAS, Dirección Regional del Ministerio del Ambiente y Petroindustrial. Los otros técnicos fueron entrevistados de forma individual.

\section{Análisis de los resultados}

La información contenida en las encuestas de productores y consumidores de semillas fue procesada y analizada en matrices y cuadros elaborados para el efecto. Se procedió a procesar las cantidades de semillas utilizadas en la producción de plántulas a través de mecanismos indirectos (número de semillas por cápsulas, peso indirecto de semillas, número de semillas por kg, porcentaje de germinación). Se elaboró una matriz para definir los actores que intervienen en el mercado de semillas forestales, así como los productores de plantones. También se dispuso de una matriz la elaboración de un directorio de los actores.

Con la información generada y las experiencias de los autores del documento se pudo contextualizar la temática de semillas forestales en las provincias señaladas. Se establece un análisis de la cadena de producción y comercialización de semillas en las diferentes regiones del Ecuador, en donde existieron experiencias semilleras por más 10 años a poyadas por la cooperación internacional y nacional.

\section{4}

\section{RESULTADOS}

\subsection{Actores del mercado y su caracterización}

En las tres provincias se identificaron 22 actores del mercado de semillas (cuadro1), los cuales están agrupados en 7 tipologías (instituciones del estado, ONGs, proyectos, viveros, OSG, productor de semillas y comercializador). Muchos de estos actores cumplen más de una función dentro de los eslabones de la cadena de producción y comercialización de semillas, para poder asegurar la producción de plantas y cumplir en cierta forma la planificación prevista. De todas formas, la disponibilidad de semillas forestales siempre es una constante del principal problema que tienen estos actores. A esto se suma el desconocimiento respecto al tema de selección y clasificación de fuentes semilleras, manejo, almacenamiento, análisis de los parámetros de la calidad entre otros.

- Ocho actores fueron identificados en Sucumbíos: cuatro instituciones estatales, las cuales poseen viveros que producen plántulas sin una planificación clara respecto a la producción de semillas y plántulas. El de Petroindustrial, produce plántulas para regalar a la población para mejorar parques y jardines, y el del CISAS que tiene un proyecto de reforestación de Jacarandá con miras a la producción de pulpa para papel y otros productos (palets, cajones para frutas, palillos de helados y baja lenguas, entre otros productos. Un proyecto / Empresa que reforesta únicamente arabisco, y tres Proveedores / comercializadores incipientes de semillas forestales y que poseen un pequeño vivero para la producción de plántulas ornamentales. 
- En Orellana se identificaron diez actores: cinco en instituciones estatales (municipio, Concejo provincial, Ministerio del Ambiente y el Proyecto Gran Sumaco [finalizado], INIAP y 1 ONG (Solidaridad Internacional) que consume semillas de varias especies forestales prioritarias. El Gobierno local y Provincial y Solidaridad Internacional en el último año trabajaron de forma organizada en la producción de plántulas en vivero de especies forestales nativas y exóticas; las nativas fueron colectadas de pocos árboles cercanos y las exóticas compradas a PROFAFOR y en Colombia. Un vivero forestal y 3 comercializadores de semillas; el vivero produce más plántulas de teca y balda para establecer macizos de plantaciones y los 3 comercializadores proveen de semillas a varios actores que demandan más especies exóticas y algunas nativas.

- En Napo se identificó tres actores semilleros; una entidad del estado que trabajó en el proyecto Gran Sumaco y consumió semillas de especies forestales nativas, cuatro organizaciones el Ministerio del Ambiente con acciones del proyecto Gran Sumaco, un vivero que produce plántulas forestales, agroforestales y ornamentales y tres proveedores informales de semillas que las venden al vivero.

- Solo 14 actores fueron entrevistados in situ durante varios días, los ocho restantes fueron entrevistados por teléfono y llenaron las encuestas y las devolvieron luego de varias semanas a los responsables de las mismas. Se observa que existe "celos" entre los responsables de viveros, producción de plántulas y establecimiento de plantaciones. Además, los que producen las semillas carecen de conocimientos técnicos elementales para el desarrollo de la temática. Sin embargo, existe la predisposición y confianza política en querer impulsar el tema entre los gobiernos locales, ONG,s y proyectos, a esto se suman los campesinos que ven una alternativa de mejorar el valor del suelo y obtener beneficios económicos en el establecimiento de plantaciones de diferentes tipos. 


\begin{tabular}{|c|c|c|c|c|c|c|c|c|}
\hline Cantones & \multicolumn{7}{|c|}{ ACTORES SEMILLEROS PROVINCIA DE SUCUMBIOS } & Total \\
\hline Lago Agrio & $\begin{array}{l}- \text {-Petro Producción } \\
-\quad \text { Centro } \\
\text { Investigaciones de y } \\
\text { Servicios Agropecuarios } \\
\text { de Sucumbíos (CISAS) }\end{array}$ & - & -Arabisco S.A. & & & - & $\begin{array}{l}\text { - Sr. Segundo Cabrera } \\
\text { - Sr. Ismael Silva } \\
\text { - Proveedores } \\
\text { informales }\end{array}$ & 6 \\
\hline $\begin{array}{l}\text { Gonzalo } \\
\text { Pizarro }\end{array}$ & $\begin{array}{lr}\text {-Ministerio } & \text { del } \\
\text { Ambiente/Proyecto } & \text { Gran } \\
\text { Sumaco } & \end{array}$ & - & - & - & - & - & - & 1 \\
\hline Sub Total & 4 & 0 & 1 & 0 & 0 & 0 & 3 & 8 \\
\hline \multicolumn{9}{|c|}{ ACTORES SEMILLEROS PROVINCIA DE ORELLANA } \\
\hline $\begin{array}{ll}\text { Fco. } & \text { de } \\
\text { Orellana } & \end{array}$ & \begin{tabular}{|l|}
-Gobierno Municipal \\
-Gobierno Provincial \\
-Ministerio \\
Ambiente/Proyecto Gran \\
Sumaco
\end{tabular} & \begin{tabular}{|l|}
-Solidaridad \\
Internacional
\end{tabular} & - & \begin{tabular}{|l|l|}
-Vivero Forestal \\
Palmar del Rio
\end{tabular} & - & - & $\begin{array}{l}\text { - PROFAFOR } \\
-\quad \text { Proveedores } \\
\text { informales }\end{array}$ & 7 \\
\hline Loreto & $\begin{array}{lr}\text {-Ministerio } & \text { del } \\
\text { Ambiente/Proyecto Gran } \\
\text { Sumaco }\end{array}$ & & & & & & & 1 \\
\hline Sub total & 5 & 1 & 0 & 1 & 0 & 0 & 3 & 10 \\
\hline
\end{tabular}




\begin{tabular}{|l|l|l|l|l|l|l|l|l|}
\hline Tena & - & & - & -Vivero Dos ríos & - & - & $\begin{array}{l}- \\
\text { informales } \\
\text {-El Semillero }\end{array}$ \\
\hline Archidona & $\begin{array}{l}\text {-Ministerio } \\
\text { Ambiente/Proyecto Gran } \\
\text { Sumaco }\end{array}$ & & & & & & \\
& 1 & & & & & & \\
\hline SubTotal & 10 & 0 & 0 & 1 & 0 & 0 & 2 & \\
\hline TOTAL & 10 & 1 & 2 & 0 & 0 & 8 \\
\hline
\end{tabular}

Cuadro 1. Actores semilleros en la amazonia del Ecuador 
Cuadro 2. Tipología de actores semilleros entrevistados en los cantones de las provincias de Sucumbíos, Orellana y Napo \begin{tabular}{|l|l|l|l|}
\hline Provincias & Cantones & Tipología de Actores \\
\cline { 3 - 3 } & & Inst.
\end{tabular}

\begin{tabular}{|c|c|c|c|c|c|c|c|c|c|c|}
\hline \multirow{2}{*}{ 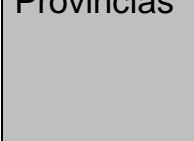 } & \multirow{2}{*}{ 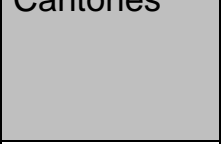 } & \\
\hline & & $\begin{array}{l}\text { Inst. } \\
\text { Estado }\end{array}$ & ONG's & $\begin{array}{l}\text { Proyect } \\
\text { os }\end{array}$ & Viveros & OSG & $\begin{array}{l}\text { Produc } \\
\text { tor }\end{array}$ & $\begin{array}{l}\text { Come } \\
\text { rcializ } \\
\text { dor }\end{array}$ & Total & $\%$ \\
\hline \multirow[t]{3}{*}{ Sucumbios } & Lago Agrio & 2 & 0 & 0 & 0 & 0 & 0 & 2 & 4 & 28,6 \\
\hline & \begin{tabular}{|l|} 
Gonzalo \\
Pizarro \\
\end{tabular} & 1 & 0 & 0 & 0 & 0 & 0 & 0 & 1 & 7,10 \\
\hline & Cascales & 1 & 0 & 0 & 0 & 0 & 0 & 0 & 1 & 7,10 \\
\hline \multirow[t]{3}{*}{ Orellana } & \begin{tabular}{|ll} 
Fco. de \\
Orellana
\end{tabular} & 3 & 1 & 0 & 0 & 0 & 0 & 0 & 4 & 28,6 \\
\hline & San Carlos & 1 & 0 & 0 & 0 & 0 & 0 & 0 & 1 & 7,10 \\
\hline & Loreto & 1 & 0 & 0 & 0 & 0 & 0 & 0 & 1 & 7,10 \\
\hline \multirow[t]{2}{*}{ Napo } & Tena & 0 & 0 & 0 & 1 & 0 & 0 & 0 & 1 & 7,10 \\
\hline & Archidona & 1 & 0 & 0 & 0 & 0 & 0 & 0 & 1 & 7,10 \\
\hline TOTAL & & 10 & 1 & 0 & 1 & 0 & 0 & 2 & 14 & 100 \\
\hline
\end{tabular}


Cuadro 3. Especies forestales nativas prioritarias en la amazonía del ecuador

\begin{tabular}{|l|l|l|}
\hline Nombre común & Nombre científico & Familia \\
\hline Guayacán Rosado & Tabebuia rosea & BIGNONIACEAE \\
\hline Cedro & Cedrela odorata & MELIACEAE \\
\hline Melina & Gmelina arbórea & VERBENACEAE \\
\hline Moral Fino & Chlorophora tinctoria & MORACEAE \\
\hline Guayacán & Tabebuia chrysantha & BIGNONIACEAE \\
\hline Ishpingo o Canela Amazónica & Ocotea quixos & LAURACEAE \\
\hline Chuncho & Cedrelinga catenaeformis & FABACEAE \\
\hline Caoba, ahuano & Sweitenia macrophylla & MELIACEAE \\
\hline Guambula & Minquartia guianensis & OLACACEAE \\
\hline Canelo & Ocotea sp. & LAURACEAE \\
\hline Bálsamo & Myroxylon balsamum & FABACEAE \\
\hline Arenillo & Erisma uncinatum & VOCHYSIACEAE \\
\hline Guarango & Parkia sp. & MIMOSACEAE \\
\hline
\end{tabular}


Cuadro 4. Volumen de semillas forestales nativas (especies prioritarias) consumido por los actores amazónicos - 2009

\begin{tabular}{|c|c|c|c|c|c|c|c|c|c|c|c|}
\hline $\begin{array}{l}\text { Nombre } \\
\text { común }\end{array}$ & $\begin{array}{l}\text { Nombre } \\
\text { científico }\end{array}$ & Familia & $\begin{array}{l}\text { Lago } \\
\text { Agrio }\end{array}$ & $\begin{array}{l}\text { Gonzalo } \\
\text { Pizarro }\end{array}$ & Cascales & $\begin{array}{l}\text { Fco. de } \\
\text { Orellana }\end{array}$ & $\begin{array}{l}\text { San } \\
\text { Carlos }\end{array}$ & Loreto & Tena & Archidona & $\begin{array}{l}\text { Total } \\
\mathrm{Kg} .\end{array}$ \\
\hline $\begin{array}{l}\text { Guayacán } \\
\text { Rosado }\end{array}$ & $\begin{array}{l}\text { Tabebuia } \\
\text { rosea }\end{array}$ & BIGNONIACEAE & & & & 20 & & & & & 20 \\
\hline Cedro & $\begin{array}{l}\text { Cedrela } \\
\text { odorata }\end{array}$ & MELIACEAE & 12 & 0,5 & 0,5 & 12,6 & 3 & & & & 28,6 \\
\hline Melina & $\begin{array}{l}\text { Gmelina } \\
\text { arbórea }\end{array}$ & VERBENACEAE & & & & 2 & & & & & 2 \\
\hline Moral Fino & $\begin{array}{l}\text { Chlorophora } \\
\text { tinctoria }\end{array}$ & MORACEAE & 1 & & & 10 & & & & & 11 \\
\hline Guayacán & $\begin{array}{l}\text { Tabebuia } \\
\text { chrysantha }\end{array}$ & BIGNONIACEAE & 2 & 0,5 & 0,5 & 33,5 & & 2 & & & 38,5 \\
\hline $\begin{array}{ll}\text { Ishpingo } & 0 \\
\text { Canela } & \\
\text { Amazónica } & \\
\end{array}$ & $\begin{array}{l}\text { Ocotea } \\
\text { quixos }\end{array}$ & LAURACEAE & & & & 12 & & & 8 & & 20 \\
\hline Chuncho & $\begin{array}{l}\text { Cedrelinga } \\
\text { catenaeformis }\end{array}$ & FABACEAE & 9,5 & & & 79 & 3 & 15 & 117 & 3,5 & 227 \\
\hline $\begin{array}{l}\text { Caoba } \\
\text { ahuano }\end{array}$ & $\begin{array}{l}\text { Sweitenia } \\
\text { macrophylla }\end{array}$ & MELIACEAE & 8 & 3 & 2 & 126,5 & 3 & 7 & 5 & & 154,5 \\
\hline Guambula & $\begin{array}{l}\text { Minquartia } \\
\text { guianensis }\end{array}$ & OLACACEAE & & & & 6,5 & & & & & 6,5 \\
\hline Canelo & Ocotea sp. & LAURACEAE & 1 & & & 7,5 & & & & & 8,5 \\
\hline Bálsamo & $\begin{array}{l}\text { Myroxylon } \\
\text { balsamum }\end{array}$ & FABACEAE & 8,5 & & & 180,5 & & & 8 & & 197 \\
\hline Arenillo & $\begin{array}{l}\text { Erisma } \\
\text { uncinatum }\end{array}$ & VOCHYSIACEAE & & & & 5 & & & & & 5 \\
\hline Guarango & Parkia sp. & MIMOSACEAE & 11 & & & & 3 & & & & 14 \\
\hline \multicolumn{3}{|l|}{ TOTAL } & 53 & 4 & 3 & 495,1 & 12 & 24 & 138 & 3,5 & 732,6 \\
\hline
\end{tabular}




\subsection{Oferta de semillas}

Actores de la oferta

Cuadro 5. Actores oferentes de semillas forestales en la amazonia

\begin{tabular}{|c|c|c|c|c|c|c|}
\hline \multirow[b]{2}{*}{$\begin{array}{l}\text { Cantone } \\
\text { s }\end{array}$} & \multicolumn{5}{|c|}{ OFERENTES DE SEMILLAS PROVINCIA DE SUCUMBIOS } & \multirow[b]{2}{*}{ Total } \\
\hline & CCL & $\mathrm{CMZ}$ & $\mathrm{CCN}$ & $\mathrm{CCl}$ & $\mathrm{PI}$ & \\
\hline $\begin{array}{l}\text { Lago } \\
\text { Agrio }\end{array}$ & - & $\begin{array}{l}\text { - Sr. Segundo } \\
\text { Cabrera } \\
\text { - Sr. Ismael Silva }\end{array}$ & - & - & - Campesino & 3 \\
\hline $\begin{array}{l}\text { Sub } \\
\text { Total }\end{array}$ & 0 & 2 & 0 & 0 & 1 & 3 \\
\hline \multicolumn{7}{|c|}{ OFERENTES DE SEMILLAS PROVINCIA DE ORELLANA } \\
\hline $\begin{array}{l}\text { Fco. de } \\
\text { Orellana }\end{array}$ & $\begin{array}{l}\text {-Almacén } \\
\text { agropecuar } \\
\text { io }\end{array}$ & - & $\begin{array}{l}\text { PROFAFO } \\
\mathrm{R}\end{array}$ & - & - Campesino & 3 \\
\hline $\begin{array}{l}\text { San } \\
\text { Carlos }\end{array}$ & - & - & - & - & -Campesino & 1 \\
\hline Sub total & 1 & 0 & 1 & 0 & 2 & 4 \\
\hline \multicolumn{7}{|c|}{ OFERENTES DE SEMILLAS PROVINCIA DE NAPO } \\
\hline Tena & - & - & - & $\begin{array}{l}\text {-El } \\
\text { Semiller } \\
\text { o }\end{array}$ & -Cesar Grefa & 2 \\
\hline SubTota & 0 & 0 & 0 & 1 & 1 & 2 \\
\hline TOTAL & 1 & 2 & 1 & 1 & 4 & 9 \\
\hline
\end{tabular}

CCL:

Casa

comerci

al local:

$\mathrm{CMZ}$ :

Comerc

ializado

$r, \mathrm{CCN}$ :

Casa

comerci

naciona

I, CCl:

Casa

comerci

internacional, PI: Proveedor informal 


\subsection{Volúmenes producidos y ofertados}

Cuadro 6. Volúmenes de semillas forestales nativas y exóticas ofertadas por tipología de actores en los cantones estudiados de las provincias de Sucumbíos, Orellana y Napo 2009

\begin{tabular}{|c|c|c|c|c|c|c|}
\hline \multirow[b]{2}{*}{$\begin{array}{l}\text { Tipología de } \\
\text { oferentes/provincia }\end{array}$} & \multirow{2}{*}{$\begin{array}{l}\text { No. de } \\
\text { individuos }\end{array}$} & \multicolumn{4}{|c|}{ Cantidad de semillas $\mathrm{Kg}$. } & \multirow{2}{*}{$\begin{array}{l}\text { Volumen } \\
\text { total } \mathrm{Kg} .\end{array}$} \\
\hline & & Nativas & $\%$ & Exóticas & $\%$ & \\
\hline \multicolumn{7}{|c|}{ Sucumbíos } \\
\hline Comercializador & 2 & 8,5 & 3,09 & 0 & 0 & 8,5 \\
\hline \multicolumn{7}{|l|}{ Orellana } \\
\hline $\begin{array}{l}\text { Casa comercial } \\
\text { local }\end{array}$ & 1 & 43 & 15,61 & 2 & 0,66 & 45 \\
\hline $\begin{array}{ll}\text { Casa comercial } \\
\text { nacional }\end{array}$ & 1 & 126 & 45,74 & 0 & 0 & 126 \\
\hline Proveedor informal & 2 & 70 & 25,41 & 303 & 99,34 & 373 \\
\hline \multicolumn{7}{|l|}{ Napo } \\
\hline Proveedor informal & 1 & 28 & 10,16 & 0 & 0 & 28 \\
\hline TOTAL & 9 & 275,5 & 100 & 305 & 100 & 580,5 \\
\hline
\end{tabular}

Cuadro 7. Oferta de semillas nativas y exóticas en los cantones de las provincias de Sucumbíos, Orellana y Napo 2009

\begin{tabular}{|l|l|l|l|l|l|}
\hline \multicolumn{5}{|l|}{ Cantidad de semillas en kg } & Total \\
\hline Provincia & Nativa & $\%$ & Exótica & $\%$ & Kg \\
\hline Sucumbíos & 8,5 & 3,09 & 0 & 0 & 8,5 \\
\hline Orellana & 239 & 86,75 & 305 & 100 & 544 \\
\hline Napo & 28 & 10,16 & 0 & 0 & 28 \\
\hline Total & 275,5 & & 305 & & 580,5 \\
\hline$\%$ & 47,46 & 100 & 52,54 & 100 & 100 \\
\hline
\end{tabular}


Cuadro 8. Volumen total de semillas nativas ofertado por cantones y especies en Sucumbíos, Orellana y Napo 2009

\begin{tabular}{|l|l|l|l|l|l|l|}
\hline Nombre común & Nombre científico & Lago Agrio & Fco. de Orellana & San Carlos & Tena & Total \\
\hline $\begin{array}{l}\text { Guayacán } \\
\text { Rosado }\end{array}$ & Tabebuia rosea & & 20 & & 20 \\
\hline Cedro & Cedrela odorata & 1 & 8 & 3 & & 12 \\
\hline Melina & Gmelina arbórea & & 2 & & 2 \\
\hline Moral Fino & Chlorophora tinctoria & & 10 & & 10 \\
\hline Guayacán & Tabebuia chrysantha & & 10 & & 10 \\
\hline $\begin{array}{l}\text { Ishpingo } \\
\text { Amazónica }\end{array}$ & Ocotea quixos & & & 3 & 8 & 8 \\
\hline $\begin{array}{l}\text { Chuncho } \\
\text { Caoba, aduano }\end{array}$ & $\begin{array}{l}\text { Cedrelinga } \\
\text { catenaeformis }\end{array}$ & 1,5 & 8 & 3 & 5 & 19,5 \\
\hline Guambula & Minquartia guianensis & & 171 & & 183 \\
\hline Canelo & Ocotea sp. & & & & & \\
\hline Bálsamo & Myroxylon balsamum & 2 & & & & \\
\hline Arenillo & Erisma uncinatum & & & & & 10 \\
\hline Guarango & Parkia sp. & & & & 3 \\
\hline Total & & & & & \\
\hline
\end{tabular}

\subsection{Precio de las semillas}

Cuadro 9. Precio de semillas forestales nativas y volumen total ofertado en los cantones estudiados de las provincias de Sucumbíos -Orellana 2009

\begin{tabular}{|l|l|l|l|}
\hline Nombre común & Nombre científico & Vol. Total $(\mathrm{kg})$ & Precio USD/kg \\
\hline $\begin{array}{l}\text { Guayacán } \\
\text { Rosado }\end{array}$ & Tabebuia rosea & 20 & $124-260$ \\
\hline Cedro & Cedrela odorata & 12 & $112-124$ \\
\hline Melina & Gmelina arbórea & 2 & 23 \\
\hline Moral Fino & Chlorophora tinctoria & 10 & 40 \\
\hline Guayacán & Tabebuia chrysantha & 10 & 90 \\
\hline $\begin{array}{l}\text { Ishpingo } \\
\text { Canela } \\
\text { Amazónica }\end{array}$ & Ocotea quixos & 8 & - \\
\hline Chuncho & & & \\
\hline Caoba, ahuano & Cedrelinga catenaeformis & 11,5 & - \\
\hline Guambula & Minquartia guianensis & - & $112-120$ \\
\hline Canelo & Ocotea sp. & - & - \\
\hline Bálsamo & Myroxylon balsamum & 10 & - \\
\hline Arenillo & Erisma uncinatum & - & - \\
\hline Guarango & Parkia sp. & 3 & 10 \\
\hline
\end{tabular}


En la amazonía se observó tres modalidades de fijación de precios de las semillas:

- Precios fijados de acuerdo a los existentes en el mercado local y nacional (los comercializadores toman como referente estos precios y fijan los suyos).

- Precios fijados en base al esfuerzo realizado en la recolección, producción y procesamiento de semillas (esta es la forma más común).

- Precios fijados de manera informal, sólo dan valor a los jornales utilizados en la recolección y los beneficios que debe tener por la venta de semillas, su viabilidad y disponibilidad.

Los precios de las semillas forestales para una misma especie tienen variación dentro del cantón y entre cantones, también existe variación de un año a otro dependiendo de la demanda sobre todo para aquellas semillas que tienen poca viabilidad $^{\mathbf{1}}$, disponibilidad y demandan mayor esfuerzo en el procesamiento de la misma. En los sitios cercanos a las fuentes semilleras los precios de las semillas por kilogramos son más bajos que en los centros poblados, aunque esta sea ofertada por el mismo vendedor.

\footnotetext{
${ }^{1}$ Viabilidad.- Es la fracción de semillas que están vivas, por ejemplo aquellas en las que se dan procesos metabólicos, aunque en forma lenta. Algunas veces la viabilidad se emplea sinónimo de vigor para indicar la habilidad del embrión para germinar y continuar el desarrollo (CONIF, 1999).
} 


\subsection{Actores de la demanda}

Cuadro 10. Tipología de actores que demandan semillas y plantas en los cantones estudiados en Sucumbíos, Orellana y Napo - 2009.

\begin{tabular}{|c|c|c|c|c|c|}
\hline \multirow[b]{2}{*}{ Cantones } & \multicolumn{4}{|c|}{ ACTORES SEMILLEROS PROVINCIA DE SUCUMBIOS } & \multirow[t]{2}{*}{ Total } \\
\hline & \begin{tabular}{l|} 
Instituciones \\
Estatales
\end{tabular} & ONG's & $\begin{array}{l}\text { Proyecto } \\
\mathrm{s}\end{array}$ & Viveros & \\
\hline Lago Agrio & \begin{tabular}{lr}
\multicolumn{3}{l}{-Petro Producción } \\
$-\quad$ Centro de \\
Investigaciones \\
Servicios \\
Agropecuarios \\
Sucumbíos \\
(CISAS)
\end{tabular} & - & $\begin{array}{l}\text {-Arabisco } \\
\text { S.A. }\end{array}$ & - & 3 \\
\hline $\begin{array}{l}\text { Gonzalo } \\
\text { Pizarro }\end{array}$ & $\begin{array}{l}- \text {-Ministerio del } \\
\text { Ambiente/Proyecto } \\
\text { Gran Sumaco }\end{array}$ & - & - & - & 1 \\
\hline Cascales & $\begin{array}{l}\text {-Ministerio del } \\
\text { Ambiente/Proyecto } \\
\text { Gran Sumaco }\end{array}$ & - & - & - & 1 \\
\hline Sub Total & 4 & 0 & 1 & 0 & 5 \\
\hline \multicolumn{6}{|c|}{ ACTORES SEMILLEROS PROVINCIA DE ORELLANA } \\
\hline $\begin{array}{ll}\text { Fco. } & \text { de } \\
\text { Orellana } & \end{array}$ & \begin{tabular}{l|}
-Gobierno \\
Municipal \\
-Gobierno \\
Provincial \\
-Ministerio del \\
Ambiente/Proyecto \\
Gran Sumaco
\end{tabular} & $\begin{array}{l}\text {-Solidaridad } \\
\text { Internacional }\end{array}$ & - & $\begin{array}{l}\text {-Vivero } \\
\text { Forestal } \\
\text { Palmar del } \\
\text { Rio }\end{array}$ & 5 \\
\hline San Carlos & $\begin{array}{l}\text { - Instituto Nacional } \\
\text { Autónomo de } \\
\text { Investigación } \\
\text { Agropecuaria } \\
\text { (INIAP) }\end{array}$ & - & - & - & 1 \\
\hline Loreto & $\begin{array}{l}\text {-Ministerio del } \\
\text { Ambiente/Proyecto } \\
\text { Gran Sumaco }\end{array}$ & - & - & - & 1 \\
\hline Sub total & 5 & 1 & 0 & 1 & 7 \\
\hline \multicolumn{6}{|c|}{ ACTORES SEMILLEROS DEL PROVINCIA DE NAPO } \\
\hline Tena & \begin{tabular}{|l|l|}
- & \\
\end{tabular} & - & - & $\begin{array}{l}\text {-Vivero Dos } \\
\text { ríos }\end{array}$ & 1 \\
\hline Archidona & $\begin{array}{l}\text {-Ministerio del } \\
\text { Ambiente/Proyecto } \\
\text { Gran Sumaco }\end{array}$ & & & & 1 \\
\hline SubTotal & 1 & 0 & 0 & 1 & 2 \\
\hline TOTAL & 10 & 1 & 1 & 2 & 14 \\
\hline
\end{tabular}




\subsection{Demanda de semillas especies prioritarias}

Cuadro 11. Demanda de semillas nativas y exóticas en los cantones de las provincias de Sucumbíos, Orellana y Napo - 2009.

\begin{tabular}{|l|l|l|l|l|l|}
\hline \multirow{2}{*}{ Provincia } & \multicolumn{4}{|l|}{ Cantidad de semillas en kg } & $\begin{array}{l}\text { Total } \\
\text { kg }\end{array}$ \\
\cline { 2 - 5 } & Nativa & $\%$ & Exótica & $\%$ & \\
\hline Sucumbíos & 60 & 8,27 & 0 & 0 & 60 \\
\hline Orellana & 524,1 & 72,23 & 7 & 100 & 531,1 \\
\hline Napo & 141,5 & 19,50 & 0 & 0 & 141,5 \\
\hline Total & $\mathbf{7 2 5 , 6}$ & & $\mathbf{7}$ & & $\mathbf{7 3 2 , 6}$ \\
\hline$\%$ & $\mathbf{9 9 , 0 4}$ & 100 & $\mathbf{0 , 9 6}$ & 100 & 100 \\
\hline
\end{tabular}

Cuadro 12. Distribución de la demanda de semillas en cantones de las provincias de Sucumbíos, Orellana y Napo - 2009.

\begin{tabular}{|l|l|l|l|l|}
\hline \multirow{2}{*}{ Cantones } & \multicolumn{2}{|l|}{ Cantidad (Kg) } & \multirow{2}{*}{ Total } \\
\cline { 2 - 4 } & Nativas & Exóticas & & \\
\hline Lago Agrio & 53 & 0 & 53 & 7,23 \\
\hline Gonzalo Pizarro & 4 & 0 & 4 & 0,55 \\
\hline Cascales & 3 & 0 & 3 & 0,41 \\
\hline Fco. de Orellana & 488,1 & 7 & 495,1 & 67,58 \\
\hline San Carlos & 12 & 0 & 12 & 1,64 \\
\hline Loreto & 24 & 0 & 24 & 3,28 \\
\hline Tena & 138 & 0 & 138 & 18,84 \\
\hline Archidona & 3,5 & 0 & 3,5 & 0,48 \\
\hline Total & $\mathbf{7 2 5 , 6}$ & $\mathbf{7}$ & $\mathbf{7 3 2 , 6}$ & $\mathbf{1 0 0}$ \\
\hline
\end{tabular}


Cuadro 13. Semillas de especies nativas más demandadas en kilogramos en los cantones estudiados de las provincias de Sucumbíos, Orellana y Napo 2009

\begin{tabular}{|c|c|c|c|c|c|c|c|c|c|c|}
\hline $\begin{array}{l}\text { Nombre } \\
\text { común }\end{array}$ & $\begin{array}{l}\text { Nombre } \\
\text { científico }\end{array}$ & $\begin{array}{l}\text { Lago } \\
\text { Agrio }\end{array}$ & \begin{tabular}{|l|} 
Gonzalo \\
Pizarro
\end{tabular} & Cascales & \begin{tabular}{|l|} 
Fco. de \\
Orellana
\end{tabular} & \begin{tabular}{|l|} 
San \\
Carlos
\end{tabular} & Loreto & Tena & Archidona & \begin{tabular}{|l|} 
Total \\
Kg.
\end{tabular} \\
\hline $\begin{array}{l}\text { Guayacán } \\
\text { Rosado }\end{array}$ & \begin{tabular}{|l|} 
Tabebuia \\
rosea
\end{tabular} & & & & 20 & & & & & 20 \\
\hline Cedro & $\begin{array}{l}\text { Cedrela } \\
\text { odorata }\end{array}$ & 12 & 0,5 & 0,5 & 12,6 & 3 & & & & 28,6 \\
\hline Melina & $\begin{array}{l}\text { Gmelina } \\
\text { arbórea }\end{array}$ & & & & 2 & & & & & 2 \\
\hline Moral fino & $\begin{array}{l}\text { Chlorophora } \\
\text { tinctoria }\end{array}$ & 1 & & & 10 & & & & & 11 \\
\hline Guayacán & $\begin{array}{l}\text { Tabebuia } \\
\text { chrysantha }\end{array}$ & 2 & 0,5 & 0,5 & 33,5 & & 2 & & & 38,5 \\
\hline $\begin{array}{l}\text { Ishpingo } 0 \\
\text { Canela } \\
\text { Amazónica }\end{array}$ & $\begin{array}{l}\text { Ocotea } \\
\text { quixos }\end{array}$ & & & & 12 & & & 8 & & 20 \\
\hline Chuncho & \begin{tabular}{|l|} 
Cedrelinga \\
catenaeformis
\end{tabular} & 9,5 & & & 79 & 3 & 15 & 117 & 3,5 & 227 \\
\hline $\begin{array}{l}\text { Caoba } \\
\text { ahuano }\end{array}$ & \begin{tabular}{|l|} 
Sweitenia \\
macrophylla
\end{tabular} & 8 & 3 & 2 & 126,5 & 3 & 7 & 5 & & 154,5 \\
\hline Guambula & $\begin{array}{l}\text { Minquartia } \\
\text { guianensis }\end{array}$ & & & & 6,5 & & & & & 6,5 \\
\hline Canelo & Ocotea sp. & 1 & & & 7,5 & & & & & 8,5 \\
\hline Bálsamo & $\begin{array}{l}\text { Myroxylon } \\
\text { balsamum }\end{array}$ & 8,5 & & & 180,5 & & & 8 & & 197 \\
\hline Arenillo & \begin{tabular}{|l} 
Erisma \\
uncinatum
\end{tabular} & & & & 5 & & & & & 5 \\
\hline \multirow[t]{2}{*}{ Guarango } & Parkia sp. & 11 & & & & 3 & & & & 14 \\
\hline & & 53 & 4 & 3 & 495,1 & 12 & 24 & 138 & 3,5 & 732,6 \\
\hline
\end{tabular}




\subsection{Dinámica del mercado}

Incidencia de proyectos en la dinámica del mercado

En la amazonia los proyectos ambientales y forestales están incidiendo en la dinámica del mercado de semillas forestales, cada año los presupuestos de las instituciones y gobiernos locales están incrementando los presupuestos participativos para la producción de plántulas y el establecimiento de plantaciones forestales. Por ej. En Orellana se prevé para el 2010 el establecimiento de más de 50 ha de plantaciones de balsa en la provincia. En Sucumbios, el CISAS prevé plantar entre $300-500$ has de Jacarandá en el 2010. Así mismo, los presupuestos para la adquisición de semillas de especies forestales nativas se han incrementado en los gobiernos locales. En este sentido, los gobiernos locales (municipios, consejos provinciales y juntas parroquiales) y proyectos ejecutados por ONGs están dinamizando el mercado de semillas y plantones forestales.

Articulación de actores del mercado

Una de las barreras que deben derribar los actores del mercado de semillas es la de la dispersión. Para actuar en el mercado se requiere la articulación de aquellos que se encuentran formando parte de los eslabones de la cadena de producción y comercialización. En la provincia de Orellana, desde hace cuatro años se ha venido trabajando en identificar los actores del sector forestal, convocarlos y tratar de organizarlos. A nivel del segmento de las semillas el tema es aún incipiente, sin embrago se están haciendo los esfuerzos con algunos eventos de capacitación para generar las bases para su organización.

Ventajas del uso de semillas de calidad

Desde el 2008 se ha iniciado los procesos de difusión de la Norma de semillas y con ello las actividades de identificación de árboles semilleros en especies forestales prioritarias. Se están estableciendo muestras de plantaciones con semilla corriente y otras con semillas de procedencia y calidad conocida para que los finqueros, reforestadores, administradores e inversionistas observen las diferencias y ventajas del uso de semillas de calidad. Aquí cabe la pregunta ¿calidad para què?. 


\subsection{Experiencias en la región y síntesis del mercado de semillas forestales en la región andina de Bolivia, Ecuador y Perú.}

En la región andina de Bolivia, Ecuador y Perú se desarrolló programas forestales y agroforestales sociales que estaban insertados en los sistemas de producción campesinos, en el manejo de cuencas hidrográficas y en la conservación de suelos en laderas, tenían como propósito garantizar la capacidad productiva de los ecosistemas, diversificar la producción campesina y mantener la diversidad biológica.

La mayoría de esos programas no consideró la calidad del material reproductivo para la producción de plantones, como consecuencia las plantaciones tenían un 'pobre crecimiento y limitado desarrollo. Así mismo, los mercados de semillas locales no logran abastecer de semillas en cantidad, calidad de forma oportuna. Además, el segmento del mercado de semillas informal integrado por campesinos y técnicos forestales era muy disperso, desconocido y producía semillas sin información técnica respecto a la calidad física, fisiológica y genética.

Con estos antecedentes INTERCOPERATION / COSUDE identificaron que el tema de semillas forestales asociado a la conservación de bosques y los actores vinculados constituye un nicho interesante en el cual se puede realizar importantes e innovadoras contribuciones, ya que el uso de semillas de calidad está poco difundido entre los oferentes y demandantes. Por otra parte, las acciones desarrolladas no se encontraban enlazadas bajo la cadena de producción y comercialización.

Una síntesis de los estudios del mercado de semillas en la región andina de Bolivia, Colombia, Chile, Ecuador y Perú impulsada por RASEFOR en 1999, estima que el mercado regional de las especies prioritarias (principalmente especies exóticas para la producción de madera para la industria) está cercano a 20 toneladas anuales, aunque ha tenido variaciones significativas en los años 1996 a 1998. Por una parte, esta cifra es apreciable si se tiene en cuenta el alto número de semillas por $\mathrm{kg}$ que tienen las especies forestales. Por otra, el precio de venta significativo que puede oscilar -sin obedecer a un cálculo riguroso de costos - entre USD 30 a USD 40 por kg. Lo anterior implica que el mercado se mueve alrededor de USD 800 000,00 anuales y millones de semillas.

Por los volúmenes de semillas consumidos, el número de actores involucrados en el mercado y las apreciables sumas de dinero movilizadas en las instituciones apara los próximos años, amerita una organización del mercado y definición de estrategias para optimizar la producción sobre todo en un sector donde tradicionalmente han predominado criterios poco rigurosos y limitadas experiencias en el tema en términos de la calidad de semillas y plantones.

La síntesis indica que para el Ecuador se reportan dos grandes grupos de demandantes, los proyectos de cooperación internacional y el conjunto compuesto por ONGs e instituciones públicas y privadas. Se menciona que para el periodo 1996-1998 se presentan cuatro especies prioritarias que tuvieron un consumo de semillas de $5667 \mathrm{~kg}$ : Tectona grandis y Schizolobium parahybum, Pinus patula y $P$. radiata. Se considera que a partir de 1995 , se reforestaba anualmente alrededor de 10 a 12 mil hectáreas (Trujillo 1999).

Así mismo, para la región andina se reporta la existencia de 155 fuentes semilleras en las categorías de fuentes identificadas y seleccionadas de las cuales 87 corresponden a especies nativas y 68 a exóticas; estas fuentes semilleras están distribuidas en Bolivia (26), Chile (32), Colombia (75), Ecuador (9) y Perú (13) (Trujillo. 1999).

Dentro de esta dinámica desde el año 2000 el Programa Andino de Fomento de Semillas Forestales - FOSEFOR que funcionó en Bolivia, Ecuador y Perú, apoyo la ejecución de proyectos relacionados directamente con el tema semillero. Entre los componentes de estos proyectos se contemplo la necesidad de determinar ¿cómo está constituido el mercado de semillas forestales en la región andina del Ecuador?.

\section{Algunos de los logros más visibles del programa FOSEFOR}

- Posicionamiento del tema a través de la generación de Normas de Semillas Forestales en cada país con criterios técnicos unificados. 
- Fortalecimiento de la cadena de producción y comercialización con iniciativas innovadoras (creación de bancos semilleros y asociaciones de semilleristas como microempresas).

Desarrollo de estudios de mercados de semillas forestales con criterios unificados, a partir de formatos preestablecidos.

- $\quad$ Sistematización, difusión de experiencias y capacitación dirigida a actores clave

- Instalación de fuentes semilleras en especies forestales nativas andinas. En la región andina se establecieron con criterios normados en las regulaciones nacionales y normas ISTA 117 fuentes semilleras en cuatro categorías genéticas diferentes para cincuenta especies forestales y agroforestales. Los proyectos bolivianos 20 fuentes semilleras en 10 especies diferentes. En Ecuador se estableció 63 fuentes semilleras en la categoría de fuentes identificadas en 20 especies. En Perú, se estableció 34 en 8 especies en 3 categorías genéticas (fuente seleccionada, rodal semillero, huerto semillero clonal).

Tanto productores como demandantes ignoran las ventajas que implica la utilización de semillas de calidad, solo por citar algunas: mayor rendimiento en las plantaciones, conocimiento de rasgos dasométricos de los futuros individuos, evita desperdicios excesivos de semillas, reducción de personal y tiempo empleado en labores de vivero.

Por otro lado, el poco acercamiento entre los actores que trabajan en este tema no facilita la difusión de las experiencias existentes ni posibilita conocer los avances desarrollados en torno a las semillas. La poca disponibilidad de semillas en cantidad, suministro oportuno y permanente para cubrir la demanda de los actores, en gran parte es el resultado de la falta de integración entre los eslabones de la cadena productiva.

\section{CONCLUSIONES:}

A nivel general, en la amazonía ecuatoriana existen limitados procesos organizativos que estimulen la tecnificación y regulación del uso de germoplasma forestal. Por esto quizás, la principal estrategia para ingresar en el mercado de semillas es la organización de los actores con la finalidad de estandarizar los procesos técnicos de producción y manejo, disponer de semillas en forma continua, diversificar y ampliar la oferta, facilitar la adquisición de semillas de calidad a los demandante y definir costos y precios de venta basados en la calidad de las semillas.

La tendencia del mercado de semillas forestales de nativas y exóticas está en aumento en la amazonia (en las provincias estudiadas no se planta pinos), ya existen algunas organizaciones instaladas para la producción de plantas, pero con limitada información respecto a la calidad de las semillas. El nivel de inversion estatal a traves de programas pilotos como el Programa PROFORESTAL del MAGAP, Ecuador se está impulsando el establecimiento de plantaciones forestales, pero nuevamente con limitado uso de semillas de calidad. En la amazonia del Ecuador, las empresas privadas financiadas a través de programas de reforestación impulsados por el Banco del Pacífico (Fideicomiso Palmar del Río) están instalando plantaciones de teca a escala mediana (más de 1500 ha entre 2006 a 2009). Se estima que el incremento en superficie se duplicará a partir del 2010. Así mismo, otra de las especies que están plantando a mediana escala y que a partir del 2010 instalaran macizos de 10 mil hectáreas en Sucumbíos es Jacarandá, para la producción de celulosa y de otros productos forestales (Bodero $2009 \mathrm{com}$. pers.).

Además, la iniciativa de los gobiernos locales (Juntas Parroquiales, municipios y consejos provinciales) es impulsar el trabajo de establecimiento de plantaciones, uno de los limitantes que 
encuentran los actores es la poca experiencia y conocimiento sobre la temática semillera y de manejo de recursos genéticos forestales. A través de organizaciones como Solidaridad Internacional y Gobiernos locales se está impulsando el tema semillero y de plantación a pequeña escala como parte de un componente del proyecto Gestión Forestal para Orellana, Amazonía del Ecuador.

\section{RECOMENDACIONES}

Organizar a los actores de la cadena con la finalidad de estandarizar los procesos técnicos de producción y manejo.

Conformar centros regionales de semillas con criterios técnicos estandarizados (para cada región, por eje.: amazónica, andina, costa/litoral) para disponer de semillas de calidad en función de la demanda, de forma continua, diversificar y ampliar la oferta.

La articular a los actores semilleros a través de un centro de producción y comercialización o Centro Semillero contribuirá a que las instituciones, organizaciones y proyectos dispongan de registros respecto a la producción de semillas y plantas,

Disponer de calendarios fenológicos adecuados para la recolección oportuna del material.

Definir un directorio de actores de cada uno de los eslabones de la cadena para disponer de información sobre aspectos de las semillas de calidad. De igual forma se prevé que los usuarios tengan un mayor acceso a la información técnica y científica sobre las especies nativas de interés.

Establecer fuentes semilleras en las categorías superiores a partir de Fuentes seleccionadas, rodales y huertos clonales para mejoramiento genético y del germoplasma utilizado. Esto genera conocimiento y experiencias sobre la temática.

Difundir la Norma nacional de semillas e ISTA a todos los actores de la cadena para estandarizar criterios en la producción y comercialización de semillas e impulsar su implementación. 


\section{Anexos}

Anexo 1 Formato de encuesta

\section{PROVEEDOR INFORMAL DE GERMOPLASMA Y PLANTONES FORESTALES - F1 INFORMACION GENERAL}

Datos generales del entrevistado:

- Nombre / Apellidos:

- Dirección:

- Institución, Proyecto, Organización o Asociación o particular

- $\quad$ Ciudad / Lugar / Provincia:

- Teléfono: correo electrónico:

- $\quad$ Actividad económica principal (comerciante, agricultura, ganadería, otro (especificar):

¿En dónde se abastecen de las semillas?

- Recolección propia en

- Bosque comunal,

- Arboles propios,

- Bosque natural,

- Plantaciones privadas establecidas

- Otros lugares (especificar)

- Compra a comuneros con moneda corriente

- Intercambio (trueque) con productos agrícolas o ganaderos. Si contestó SI, preguntar: (Qué productos son los más comunes que utilizan en el intercambio?)

- Compra en el mercado local

- Compra en casas comerciales

- $\quad$ Otros mecanismos (especificar cuáles)

Si hace recolección propia, ¿Qué criterios utiliza para seleccionar los árboles de dónde obtiene las semillas?

¿Qué especies colectan (nombre común) y qué volumen?

\begin{tabular}{|c|c|c|c|c|c|}
\hline \multirow{2}{*}{$\begin{array}{l}\text { Fuente } \\
\text { Semillera }\end{array}$} & \multirow[b]{2}{*}{ Especie } & \multicolumn{3}{|l|}{ Año } & \multirow[b]{2}{*}{ № semillas / kg } \\
\hline & & $\begin{array}{l}\text { Volumen } \\
(\mathrm{Kg}) .\end{array}$ & $\begin{array}{l}\text { US } \$ / K g \\
\text { (precio } \\
\text { venta) }\end{array}$ & Proveedor & \\
\hline & & & & & \\
\hline & & & & & \\
\hline & & & & & \\
\hline & & & & & \\
\hline & & & & & \\
\hline & & & & & \\
\hline & & & & & \\
\hline & & & & & \\
\hline & & & & & \\
\hline
\end{tabular}


¿Qué procedimientos utilizan para seleccionar las semillas que van a vender?

¿A quiénes venden las semillas? (expresar en porcentaje de la cantidad total vendida $(\mathrm{Kg})$ )

- A miembros de la comuna

- A las empresas madereras

- A casas comerciales

- A instituciones del Estado

- A ONG's

- A cooperativas campesinas

- A viveros

¿En dónde venden las semillas?

- $\quad$ En el mercado local

- En la comuna

- $\quad$ Entrega directa al cliente por pedido previo

- Otros lugares (detallar)

- $\quad$ Provee información sobre la calidad física y fisiológica de la semilla: SI o NO y de qué tipo?.

¿Utiliza las semillas para desarrollar sus propios viveros?
- SI
NO

Si contestó SI, solicitar el detalle la cantidad de semillas $(\mathrm{kg})$ que utiliza y cuantas plántulas produce anualmente.

\begin{tabular}{|l|l|l|l|}
\hline Especie & $\begin{array}{l}\text { Kg. / semilla a } \\
\text { utilizar en } \\
\text { vivero }\end{array}$ & $\begin{array}{l}\text { Número de } \\
\text { plantas a a } \\
\text { producir / kg }\end{array}$ & $\begin{array}{l}\text { Precio } \\
\text { plántulas } \\
\text { (USD/planta) }\end{array}$ \\
\hline & & & \\
\hline & & & \\
\hline & & & \\
\hline & & & \\
\hline & & & \\
\hline & & & \\
\hline & & & \\
\hline & & & \\
\hline & & & \\
\hline & & & \\
\hline & & & \\
\hline
\end{tabular}

¿Con qué frecuencia vende las semillas? (se pretende identificar el tiempo que la persona o grupo dedica a esta actividad)

Definir las características del negocio

- Individual 
- Familiar

- Comunal

¿Cómo fijan el precio de las semillas?

¿Han recibido cursos de capacitación sobre la manera de seleccionar los árboles y recoger semillas?

14. Otros comentarios relevantes del entrevistado.

Cuáles son los problemas más frecuentes que debe enfrentar y que están relacionados con la Calidad y adquisición de las semillas forestales (nativas y exóticas).

16. ¿Cuántos años trabaja en la actividad semillera?:

Recolector de información:

Fecha:

Precisiones para el llenado del formulario

Semillas: cualquier parte del vegetal que se utilice para la producción de una nueva planta.

Volumen: puede ser expresado en $\mathrm{Kg}$. o número de estacas.

Precio: el precio debe ser expresado en US/kg. o US\$ / numero de estacas (por favor especificar).

Recomendamos utilizar el nombre científico.

- Fuente semillera, calificarla bajo los criterios de la Norma de semillas Ecuador: Huerto Semillero Genéticamente Comprobado (HSC), Huerto Semillero No Comprobado (HSNC), Rodal Semillero (RS), Fuente Seleccionada (FS), Fuente Identificada (FI).

- Proveedor: Centro semillero (CS), Casas comerciales locales (CCL), Importación (IM), Recolección en bosques comunales (RBC), Recolección en fuentes semilleras Registradas (RFR), Otros (OT).

Semilla de calidad: es aquella que posee información técnica respecto a la calidad física (sin enfermedad), fisiológica (germina bien y uniformemente) y genética (proviene de árboles superiores al promedio de la fuente semillera seleccionada)

Ipr/15ago 2009/semillas amazonía ecuador 


\section{Anexo 2 \\ Políticas y normas para regular la producción, uso y comercialización de semillas forestales}

\section{CODIFICACIÓN DE LA LEY FORESTAL Y DE CONSERVACIÓN DE ÁREAS NATURALES Y VIDA SILVESTRE (2004-017).}

TITULO I

De los Recursos Forestales

CAPITULO VIII. De la investigación y capacitación Forestales

Art. 53.- Créase bajo la dependencia del Ministerio del Ambiente, el Programa de Semillas Forestales, como órgano técnico administrativo encargado de la promoción y formación de viveros y huertos semilleros; del acopio, conservación y suministro de semillas certificadas a precios de costo; y, las demás actividades que le fije el reglamento.

Iguales actividades podrá cumplir la empresa privada bajo control ministerial.

TITULO II. DE LAS ÁREAS NATURALES Y DE LA FLORA Y FAUNA SILVESTRES

CAPITULO I. Del patrimonio nacional de áreas naturales

d) Establecer zoocriaderos, viveros, jardines de plantas silvestres y estaciones de investigación para la reproducción y fomento de la flora y fauna silvestres;

CAPITULO III. De la conservación de flora u fauna silvestres

Art. 73.- La flora y fauna silvestres son de dominio del Estado y corresponde al Ministerio del Ambiente su conservación, protección y administración, para lo cual ejercerá las siguientes funciones:

a) Controlar la cacería, recolección, aprehensión, transporte y tráfico de animales y otros elementos de la fauna y flora silvestres;

TITULO IV

$\begin{array}{lllllll}\text { DE LAS INFRACCIONES A } & \text { A } & \text { LA } & \text { PRESENTE } & \text { LEY } & Y\end{array}$ SU JUZGAMIENTO

\section{CAPITULO I}

Art. 80.- Quien comercialice productos forestales, animales vivos, elementos constitutivos o productos de la fauna silvestre, especialmente de la flora o productos forestales diferentes de la madera, sin la respectiva autorización, será sancionado administrativamente con una multa de quinientos a mil salarios mínimos vitales generales.

\section{CAPITULO II}

De la jurisdicción y del procedimiento administrativo 
Art. 97.- Los productos forestales decomisados serán vendidos por la propia autoridad sancionadora inmediatamente después de dictada la resolución de primera instancia, bajo su personal responsabilidad.

Ejecutoriada la resolución condenatoria en la vía administrativa o en la vía jurisdiccional, el $\$ 0 \%$ del valor de la venta del decomiso se entregará al denunciante o al servidor público forestal que haya procedido de oficio, y el restante $50 \%$ ingresará al Fondo Forestal. De ser revocada la resolución, el valor total se entregará al dueño del producto decomisado.

Art. 98.- Los bienes diferentes de los productos forestales y de flora y fauna decomisados en conformidad con lo dispuesto en el Art. 80 de esta Ley, serán vendidos en pública subasta, siguiendo el procedimiento establecido en las leyes respectivas.

NORMA PARA EL MANEJO FORESTAL SUSTENTABLE PARA EL APROVECHAMIENTO DE MADERA EN BOSQUE HUMEDO.

\section{CAPITULO I. PROGRAMA DE APROVECHAMIENTO FORESTAL SUSTENTABLE.}

Art. 11. Para efectos del aprovechamiento maderero los árboles encontrados en el inventario o registrados en el censo, deberán ser clasificados bajo los siguientes criterios según el caso:

Arboles de reserva cuyo DAP es igual o superior al DMC que no será aprovechado y que no ha sido clasificado como árbol protegido. Deberá considerarse como árboles de reserva aquellos que tienen buenas características para la producción de semillas.

Para establecer el número de árboles de reserva, obligatoriamente se consideran algunos criterios (ver Norma BH).

\section{NORMA DE SEMILLAS FORESTALES PARA EL ECUADOR}

La Norma de Semillas Forestales del Ecuador, vigente desde febrero de 2004, es un instrumento que puesto en ejecución e implementación apoyará en la orientación y reglamentación del uso de semillas en el país. Con los procesos de modernización y descentralización implementados por el estado en algunos sectores, como el forestal, la norma busca regular el comercio de semillas a nivel local, regional y nacional.

La Norma de semillas forestales contiene:

11 capítulos; del 1-6 trata de las categorías y definiciones para establecimiento de fuentes semilleras, el control y la supervisión par parte de la autoridad ambiental y el propietario.

Señala los mecanismos generales para la recolección de semillas. Del capítulo 7-10 trata de los criterios para la comercialización de semillas forestales, la información que debe contener, las características de los envases y etiquetas. Así mismo, especifica los mecanismos para la importación de semillas y los criterios de la calidad. El capítulo 11 trata de las prohibiciones y denuncias.

La norma de semillas forestales enfatiza en el Registro de las personas que realizan la actividad semillera (productores y comerciantes), las fuentes semilleras instaladas y aprobadas por el Ministerio para la producción de semillas, los inspectores de semillas.

El propósito de la Norma de semillas es:

- Definir indicadores para la producción de semillas forestales

- Establecer mecanismos para la comercialización de semillas forestales con calidad física y fisiológica conocidas. 
- Establecer y mantener un registro de fuentes semilleras, productores, comercializadores e inspectores de semillas forestales.

- Propone un mecanismo de supervisión del manejo de semillas forestales

- Establece condiciones para el comercio de semillas forestales acorde con la política forestal.

Una de las debilidades de la aplicación de la Norma como instrumento a diferencia de otras (aprovechamiento de madera bth, bs y ba) es la limitada difusión y socialización en el ámbito nacional, solo se lo realizó con mayor fuerza en la región andina. Así mismo, el Ministerio del Ambiente regula el comercio de semillas de forma incipiente y muy localizada, y donde lo hace será por una suerte de interés de los técnicos capacitados en cada una de las Direcciones Regionales u Oficinas Técnicas del mismo. En este sentido, se requiere una campaña de difusión a todos los niveles (Directivos, tomadores de decisiones, productores y comercializadores de semillas, educadores, técnicos de campo, administradores de instituciones que ejecutan pagos de adquisiciones, entre otros.). 
Anexo 3

Roles de los actores que conforman la cadena de producción y comercialización de semillas forestales en el Ecuador.

\begin{tabular}{|c|c|}
\hline Actores & Roles \\
\hline $\begin{array}{l}\text { Propietarios } \\
\text { FS/recolectores }\end{array}$ & $\begin{array}{l}\text { - Recolectar semillas forestales en FS y árboles seleccionados } \\
\text { - Manejar la FS de acuerdo a planes de manejo } \\
\text { - Utilizar los criterios técnicos, equipos y materiales para la recolección de SF } \\
\text { - Proteger y conservar las FS } \\
\text { - Llevar un registro del volumen de semillas forestales cosechados } \\
\text { - Entregar las semillas forestales al Centro de acopio bajo, criterios y acuerdos } \\
\text { establecidos } \\
\text { - Apoyar al centro de acopio en la selección de nuevas fuentes semilleras } \\
\text { - Registrar la FS en el distrito u Oficina Técnica correspondiente }\end{array}$ \\
\hline Comercializadores & $\begin{array}{l}\text { - Comercializar SF del Centro de acopio bajo acuerdos } \\
\text { - Asegurar el cuidado de SF que garantice la calidad declarada } \\
\text { - Tener un registro de venta se SF } \\
\text { - Apoyar la difusión y promoción del uso de SF de calidad } \\
\text { - Registrar los comentarios de la calidad de SF por parte de usuarios } \\
\text { - Registrarse como vendedor de SF en el Distrito Regional u Oficina Técnica } \\
\text { correspondiente }\end{array}$ \\
\hline Demandantes & $\begin{array}{l}\text { - Adquirir SF de calidad que provengan del Centro semillero garantizado y } \\
\text { Registrado } \\
\text { - Hacer conocer oportunamente al Centro semillero sus requerimientos } \\
\text { - Apoyar la difusión y promoción del uso de SF de calidad }\end{array}$ \\
\hline Reguladores & $\begin{array}{l}\text { - Analizar la calidad física y fisiológica de las SF bajo normas ISTA } \\
\text { - Establecer y difundir costos de análisis de SF } \\
\text { - Registrar como laboratorio de análisis en Distrito Regional u Oficina Técnica } \\
\text { correspondiente } \\
\text { - Registrar e informar al Centro semillero y Ministerio del Ambiente de los } \\
\text { resultados de las SF } \\
\text { - Vender capacitación técnica a usuarios de SF } \\
\text { - Acordar con OG, ONGs, proyectos, profesionales los criterios de calidad para las } \\
\text { semillas forestales }\end{array}$ \\
\hline $\begin{array}{l}\text { Ministerio } \\
\text { Ambiente }\end{array}$ & $\begin{array}{l}\text {-Aplicar la Norma de SF en las actividades correspondientes } \\
\text { - Evaluar y registrar Fuentes semilleras - FS } \\
\text { - Emitir el Registro y Aval a laboratorio de análisis SF } \\
\text { - Emitir el Registro y aval a Centros semilleros } \\
\text { - Emitir el Registro y aval a comercializadores de semillas } \\
\text { - Abrir archivo de semillas en el Registro Forestal. } \\
\text {-Impulsar en los demandantes la compra de SF de calidad a través de centros } \\
\text { registrados }\end{array}$ \\
\hline
\end{tabular}




\begin{tabular}{|l|l|}
\hline Centros semillero & - Registrarse como comercializador de SF en el Distrito Regional correspondiente. \\
& - Manejar las FS seleccionadas en alianza con los propietarios de las mismas. \\
& Acopio y manejo \\
& - Acopiar SF por lotes de las FS seleccionadas y registradas. \\
& - Asegurar la procedencia y calidad de SF. \\
& - Procesar y almacenar SF garantizando su viabilidad. \\
& - Seleccionar nuevas FS en base a la demanda. \\
& - Comercialización \\
& conocida. \\
& - Conocer y reaccionar a los requerimientos de la demanda de SF \\
& - Establecer precio de SF en base a costos de producción. \\
& Difusión / promoción \\
& - Promocionar el uso de SF de calidad a los usuarios. \\
& - Brindar información y capacitación a los usuarios de semillas. \\
& - Diseñar estrategia de promoción de SF \\
\hline
\end{tabular}




\section{Bibliografia}

CARRASCO, ALFREDO. 1998. Aproximación metodológica para determinar el mercado de las semillas forestales en el área Andina. Red Andina de Semillas Forestales - RASEFOR / RASEFOR, COSUDE - INTERCOPERATION. Costa Rica.

CENTRAL ECUATORIANA DE SERVICIOS AGRÍCOLAS. 1992. Usos tradicionales de las especies forestales nativas del Ecuador [usos medicinales] CESA.Quito. Ecuador.

FUNDACIÓN ARCOIRIS Y ASOCIACIÓN DE AGRÓNOMOS INDÍGENAS DEL CAÑAR, 2004. Estudio de mercado de semillas forestales de especies nativas y exóticas en las provincias de Loja, Azuay y Cañar (consolidado). 50 p.

ORDOÑEZ, L., ARBELÁEZ, M. y PRADO L. (Com-Eds). 2004. Manejo de semillas forestales nativas de la Sierra ecuatoriana y Norte del Perú. Ecopar- Fosefor-Samiri. Quito, Ecuador. $151 \mathrm{p}$.

PRADO, L. 2002. El mercado de semillas forestales de especies nativas en los cantones de Cañar, Azogues, El Tambo, Suscal y Cuenca, Ecuador. Cañar, Ecuador, Asociación de Agrónomos Indígenas del Cañar, Proyecto Centro de manejo y propagación de especies forestales nativas andinas del Cañar. $55 \mathrm{p}$.

PRADO, L. 2002. Estudio de mercado de semillas forestales nativas y exóticas en siete cantones de Loja, Ecuador. Loja, Ecuador, Fundación Ecológica Arcoiris, Proyecto Producción y comercialización de semillas de especies nativas en el cantón Loja. 62 p.

RODRIGUEZ Y NIETO, 1999. Investigación en semillas forestales nativas. Corporación Nacional de Investigación y Fomento Forestal - CONIF: Serie Técnica No 42. Santa Fe de Bogotá. 89p.

SAMANIEGO, C., ORDOÑEZ, O., PRADO, L. y MOROCHO, M. 2005. Las fuentes semilleras y semillas forestales nativas de Loja y Cañar: participación social en el manejo. Loja, Ecuador. Fundación Arcoiris-Fosefor-Asociación de Agrónomos Indígenas del Cañar. 80 p.

TORRICO, G., REA L. y BECK, S. 1997. Estudio sobre los árboles y arbustos nativos de uso múltiple en los departamentos de Cochabamba y Chuquisaca (valles secos interandinos). Programa de Bosques Nativos Andinos - PROBONA. La Paz. Bolivia.

TRUJILLO, E.1999. Síntesis del mercado de semillas forestales para Región Andina de

Bolivia, Ecuador, Perú, Chile y Colombia. Fundación INTERCOOPERATION - COSUDE, Quito, Ecuador. 


\section{WORKING PAPERS IN THIS SERIES}

1. Agroforestry in the drylands of eastern Africa: a call to action

2. Biodiversity conservation through agroforestry: managing tree species diversity within a network of community-based, nongovernmental, governmental and research organizations in western Kenya.

3. Invasion of prosopis juliflora and local livelihoods: Case study from the Lake Baringo area of Kenya

4. Leadership for change in farmers organizations: Training report: Ridar Hotel, Kampala, 29th March to 2nd April 2005.

5. Domestication des espèces agroforestières au Sahel : situation actuelle et perspectives

6. Relevé des données de biodiversité ligneuse: Manuel du projet biodiversité des parcs agroforestiers au Sahel

7. Improved land management in the Lake Victoria Basin: TransVic Project's draft report.

8. Livelihood capital, strategies and outcomes in the Taita hills of Kenya

9. Les espèces ligneuses et leurs usages: Les préférences des paysans dans le Cercle de Ségou, au Mali

10. La biodiversité des espèces ligneuses: Diversité arborée et unités de gestion du terroir dans le Cercle de Ségou, au Mali

11. Bird diversity and land use on the slopes of Mt. Kilimanjaro and the adjacent plains, Tanzania

12. Water, women and local social organization in the Western Kenya Highlands

13. Highlights of ongoing research of the World Agroforestry Centre in Indonesia

14. Prospects of adoption of tree-based systems in a rural landscape and its likely impacts on carbon stocks and farmers' welfare: The FALLOW

Model Application in Muara Sungkai, Lampung, Sumatra, in a 'Clean Development Mechanism' context

15. Equipping integrated natural resource managers for healthy Agroforestry landscapes.

17. Agro-biodiversity and CGIAR tree and forest science: approaches and examples from Sumatra.

18. Improving land management in eastern and southern Africa: A review of policies.

19. Farm and household economic study of Kecamatan Nanggung, Kabupaten Bogor, Indonesia: A socio-economic base line study of Agroforestry innovations and livelihood enhancement.

20. Lessons from eastern Africa's unsustainable charcoal business.

21. Evolution of RELMA's approaches to land management: Lessons from two decades of research and development in eastern and southern Africa

22. Participatory watershed management: Lessons from RELMA's work with farmers in eastern Africa.

23. Strengthening farmers' organizations: The experience of RELMA and ULAMP.

24. Promoting rainwater harvesting in eastern and southern Africa.

25. The role of livestock in integrated land management.

26. Status of carbon sequestration projects in Africa: Potential benefits and challenges to scaling up.

27. Social and Environmental Trade-Offs in Tree Species Selection: A Methodology for Identifying Niche Incompatibilities in Agroforestry [Appears as AHI Working Paper no. 9]

28. Managing tradeoffs in agroforestry: From conflict to collaboration in natural resource management. [Appears as AHI Working Paper no. 10]

29. Essai d'analyse de la prise en compte des systemes agroforestiers pa les legislations forestieres au Sahel: Cas du Burkina Faso, du Mali, du Niger et du Senegal.

30. Etat de la recherche agroforestière au Rwanda etude bibliographique, période 1987-2003

31. Science and technological innovations for improving soil fertility and management in Africa: A report for NEPAD's Science and Technology Forum. 
32. Compensation and rewards for environmental services.

33. Latin American regional workshop report compensation.

34. Asia regional workshop on compensation ecosystem services.

35. Report of African regional workshop on compensation ecosystem services.

36. Exploring the inter-linkages among and between compensation and rewards for ecosystem services CRES and human well-being

37. Criteria and indicators for environmental service compensation and reward mechanisms: realistic, voluntary, conditional and pro-poor

38. The conditions for effective mechanisms of compensation and rewards for environmental services.

39. Organization and governance for fostering Pro-Poor Compensation for Environmental Services.

40. How important are different types of compensation and reward mechanisms shaping poverty and ecosystem services across Africa, Asia \& Latin America over the Next two decades?

41. Risk mitigation in contract farming: The case of poultry, cotton, woodfuel and cereals in East Africa.

42. The RELMA savings and credit experiences: Sowing the seed of sustainability

43. Yatich J., Policy and institutional context for NRM in Kenya: Challenges and opportunities for Landcare.

44. Nina-Nina Adoung Nasional di So! Field test of rapid land tenure assessment (RATA) in the Batang Toru Watershed, North Sumatera.

45. Is Hutan Tanaman Rakyat a new paradigm in community based tree planting in Indonesia?

46. Socio-Economic aspects of brackish water aquaculture (Tambak) production in Nanggroe Aceh Darrusalam.

47. Farmer livelihoods in the humid forest and moist savannah zones of Cameroon.

48. Domestication, genre et vulnérabilité : Participation des femmes, des Jeunes et des catégories les plus pauvres à la domestication des arbres agroforestiers au Cameroun.

49. Land tenure and management in the districts around Mt Elgon: An assessment presented to the Mt Elgon ecosystem conservation programme.

50. The production and marketing of leaf meal from fodder shrubs in Tanga, Tanzania: A propoor enterprise for improving livestock productivity.

51. Buyers Perspective on Environmental Services (ES) and Commoditization as an approach to liberate ES markets in the Philippines.

52. Towards Towards community-driven conservation in southwest China: Reconciling state and local perceptions.

53. Biofuels in China: An Analysis of the Opportunities and Challenges of Jatropha curcas in Southwest China.

54. Jatropha curcas biodiesel production in Kenya: Economics and potential value chain development for smallholder farmers

55. Livelihoods and Forest Resources in Aceh and Nias for a Sustainable Forest Resource Management and Economic Progress

56. Agroforestry on the interface of Orangutan Conservation and Sustainable Livelihoods in Batang Toru, North Sumatra.

57. Assessing Hydrological Situation of Kapuas Hulu Basin, Kapuas Hulu Regency, West Kalimantan.

58. Assessing the Hydrological Situation of Talau Watershed, Belu Regency, East Nusa Tenggara.

59. Kajian Kondisi Hidrologis DAS Talau, Kabupaten Belu, Nusa Tenggara Timur.

60. Kajian Kondisi Hidrologis DAS Kapuas Hulu, Kabupaten Kapuas Hulu, Kalimantan Barat.

61. Lessons learned from community capacity building activities to support agroforest as sustainable economic alternatives in Batang Toru orang utan habitat conservation program (Martini, Endri et al.) 
62. Mainstreaming Climate Change in the Philippines.

63. A Conjoint Analysis of Farmer Preferences for Community Forestry Contracts in the Sumber Jaya Watershed, Indonesia.

64. The highlands: a shared water tower in a changing climate and changing Asia

65. Eco-Certification: Can It Deliver Conservation and Development in the Tropics.

66. Designing ecological and biodiversity sampling strategies. Towards mainstreaming climate change in grassland management.

67. Towards mainstreaming climate change in grassland management policies and practices on the Tibetan Plateau

68. An Assessment of the Potential for Carbon Finance in Rangelands

69 ECA Trade-offs Among Ecosystem Services in the Lake Victoria Basin.

69. The last remnants of mega biodiversity in West Java and Banten: an in-depth exploration of RaTA (Rapid Land Tenure Assessment) in Mount Halimun-Salak National Park Indonesia

70. Le business plan d'une petite entreprise rurale de production et de commercialisation des plants des arbres locaux. Cas de quatre pépinières rurales au Cameroun.

71. Les unités de transformation des produits forestiers non ligneux alimentaires au Cameroun. Diagnostic technique et stratégie de développement Honoré Tabuna et Ingratia Kayitavu.

72. Les exportateurs camerounais de safou (Dacryodes edulis) sur le marché sous régional et international. Profil, fonctionnement et stratégies de développement.

73. Impact of the Southeast Asian Network for Agroforestry Education (SEANAFE) on agroforestry education capacity.

74. Setting landscape conservation targets and promoting them through compatible land use in the Philippines.

75. Review of methods for researching multistrata systems.

76. Study on economical viability of Jatropha curcas L. plantations in Northern Tanzania assessing farmers' prospects via cost-benefit analysis

77. Cooperation in Agroforestry between Ministry of Forestry of Indonesia and International Center for Research in Agroforestry

78. "China's bioenergy future. an analysis through the Lens if Yunnan Province

79. Land tenure and agricultural productivity in Africa: A comparative analysis of the economics literature and recent policy strategies and reforms

80. Boundary organizations, objects and agents: linking knowledge with action in agroforestry watersheds

81. Reducing emissions from deforestation and forest degradation (REDD) in Indonesia: options and challenges for fair and efficient payment distribution mechanisms

82. Mainstreaming climate change into agricultural education: challenges and perspectives

83. Challenging conventional mindsets and disconnects in conservation: the emerging role of eco-agriculture in Kenya's landscape mosaics

84. Lesson learned RATA garut dan bengkunat: suatu upaya membedah kebijakan pelepasan kawasan hutan dan redistribusi tanah bekas kawasan hutan

85. The emergence of forest land redistribution in Indonesia

86. Commercial opportunities for fruit in Malawi

87. Status of fruit production processing and marketing in Malawi

88. Fraud in tree science

89. Trees on farm: analysis of global extent and geographical patterns of agroforestry

90. The springs of Nyando: water, social organization and livelihoods in Western Kenya

91. Building cpacity toward region-wide curriculum and teaching materials development in agroforestry education in Southeast Asia

92. Overview of biomass energy technology in rural Yunnan (Chinese - English abstract)

93. A pro-growth pathway for reducing net GHG emissions in China

94. Analysis of local livelihoods from past to present in the central Kalimantan Ex- 
95. Mega Rice Project area

95. Constraints and options to enhancing production of high quality feeds in dairy production in Kenya, Uganda and Rwanda

96. Agroforestry education in the Philippines: status report from the Southeast Asian Network for Agroforestry Education (SEANAFE)

2010

97. Economic viability of Jatropha curcas L. plantations in Northern Tanzania- assessing farmers' prospects via cost-benefit analysis.

98. Hot spot of emission and confusion: land tenure insecurity, contested policies and competing claims in the central Kalimantan Ex-Mega Rice Project area

99. Agroforestry competences and human resources needs in the Philippines

100. CES/COS/CIS paradigms for compensation and rewards to enhance environmental Services

101. Case study approach to region-wide curriculum and teaching materials development in agroforestry education in Southeast Asia

102. Stewardship agreement to reduce emissions from deforestation and degradation (REDD): Lubuk Beringin's Hutan Desa as the first village forest in Indonesia

103. Landscape dynamics over time and space from ecological perspective

104. A performance-based reward for environmental services: an action research case of "RiverCare" in Way Besai sub-watersheds, Lampung, Indonesia

105. Smallholder voluntary carbon scheme: an experience from Nagari Paningahan, West Sumatra, Indonesia

106. Rapid Carbon Stock Appraisal (RACSA) in Kalahan, Nueva Vizcaya, Philippines

107. Tree domestication by ICRAF and partners in the Peruvian Amazon: lessons learned and future prospects in the domain of the Amazon Initiative eco-regional program

108. Memorias del Taller Nacional: "Iniciativas para Reducir la Deforestación en la region Andino - Amazónica", 09 de Abril del 2010. Proyecto REALU Peru

109. Percepciones sobre la Equidad y Eficiencia en la cadena de valor de REDD en Perú Reporte de Talleres en Ucayali, San Martín y Loreto, 2009. Proyecto REALU-Perú.

110. Reducción de emisiones de todos los Usos del Suelo. Reporte del Proyecto REALU Perú Fase 1

111. Programa Alternativas a la Tumba-y-Quema (ASB) en el Perú. Informe Resumen y Síntesis de la Fase II. 2da. versión revisada

112. Estudio de las cadenas de abastecimiento de germoplasma forestal en la amazonía Boliviana

113. Biodiesel in the Amazon

114. Estudio de mercado de semillas forestales en la amazonía Colombiana

115. Estudio de las cadenas de abastecimiento de germoplasma forestal en Ecuador 
The World Agroforestry Centre is an autonomous, non-profit research organization whose vision is a rural transformation in the developing world where smallholder households

strategically increase their use of trees in agricultural landscapes to improve their food security, nutrition, income, health, shelter, energy resources and environmental sustainability. The Centre generates science-base knowledge about the diverse role that trees play in agricultural landscapes, and uses its research to advance policies and practices that benefit the poor and the environment.

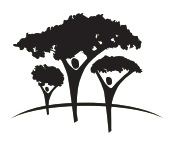

United Nations Avenue, Gigiri - PO Box 30677 - 00100 Nairobi, Kenya Tel: +254 207224000 or via USA +1 6508336645

Fax: +254207224001 or via USA +1 6508336646

www.worldagroforestry.org 